\title{
Capsule Commentary on Jin et. al., Cost-Effectiveness of Primary HPV Testing, Cytology and Co-testing as Cervical Cancer Screening for Women above Age 30 Years
}

\author{
Judith Walsh, MD, MPH \\ $\mathrm{J}$ Gen Intern Med 31(11): 1358 \\ DOI: $10.1007 / \mathrm{s} 11606-016-3796-\mathrm{x}$ \\ (๑) Society of General Internal Medicine 2016
}

Division of General Internal Medicine, Women's Health Center of Excellence, University of California San Francisco, San Francisco, CA, USA.

I a creative retrospective cohort study, Jin and colleagues evaluated 99,549 women who received co-testing with cytology and HPV for primary cervical cancer screening during a 3 -year screening interval. ${ }^{1}$ They modeled three primary screening strategies, (1) primary cytology, (2) co-testing with cytology and HPV and (3) HPV testing alone. Co-testing was the most sensitive followed by primary HPV and primary cytology. The positive predictive value was highest for primary HPV testing $(12 \%)$, followed by co-testing $(10.3 \%)$ and primary cytology $(9.6 \%)$. The negative predictive value was comparable for the three testing strategies. Primary HPV testing detected more cases than cytology alone. Co-testing detected more cases, at a higher cost. The authors conclude that primary HPV testing is more effective and less expensive than primary cytology and is a cost-effective alternative to co-testing.

Should this study change our approach to cervical cancer screening? An important caveat to consider is that "costeffectiveness" cannot be shown unless the intervention is actually shown to be effective. Although there is some evidence to support primary HPV testing for cervical cancer screening, the evidence is limited. Limitations of the HPV alone strategy are the reliance on CIN3 plus as the main outcome rather than cervical cancer mortality and on the relatively short follow-up of the primary HPV screening studies so far.

Although the American Society for Colposcopy and Cervical Cytology and the Society of Gynecologic Oncology suggest that HPV testing is an alternative screening option, this approach is not broadly endorsed. ${ }^{2}$ USPSTF guidelines for women $\geq 30$ years old are that either primary cytology or co-testing is a reasonable cervical cancer screening alternative. $^{3}$ The American College of Gynecology recommends primary cytology or co-testing, with co-testing as the "preferred screening strategy." They state that "primary HPV testing every 3 years can be considered for women $\geq 25$," while acknowledging that the options of cytology alone or co-testing "remain the options specifically recommended in most major society guidelines." In conclusion, although primary HPV testing is not broadly endorsed by major society guidelines, if it is performed, it appears to be a cost-effective alternative to other more established screening strategies.

Corresponding Author: Judith Walsh, MD, MPH; Division of General Internal Medicine, Women's Health Center of ExcellenceUniversity of California San Francisco, San Francisco, CA, USA (e-mail: judith.walsh@ucsf.edu).

\section{Compliance with ethical standards:}

Conflict of interest: The author has no conflicts of interest with this article.

\section{REFERENCES}

1. Jin XW, Lipold L, Foucher J, Sikon A, Brainard J, Belinson J, Schramm S, Nottingham K, Hu B, Rothberg RB. Cost-effectiveness of primary HPV testing. Cytology and co-testing as cervical. J Gen Intern Med. 2016. doi:10. 1007/s11606-016-3772-50.

2. Huh WK, Ault KA, Chelmow D, et al. Use of primary high-risk human papillomavirus testing for cervical cancer screening: interim clinical guidance. Gynecol Oncol. 2015;136(2):178-182. doi:10.1016/j.ygyno.2014.12.022.

3. Moyer VA. U.S. Preventive Services Task Force. Screening for cervical cancer: US Preventive Services Task Force recommendation statement. Ann Intern Med. 2012;156(12):880-891. doi:10.7326/0003-4819-156-12201206190-00424. W312.

4. Cervical cygology screening. ACOG Practice Bulletin No. 157. American College of Obstetricians and Gynecologists. Obstet Gynecol 2016: 127:e1.

Published online July 6, 2016 